\title{
miRNome of inflammatory breast cancer
}

\author{
Diana V Maltseva ${ }^{1 \dagger}$, Vladimir V Galatenko ${ }^{1,2 \dagger}$, Timur R Samatov ${ }^{1 *+}$, Svetlana O Zhikrivetskaya ${ }^{1}$, Nadezhda A Khaustova ${ }^{1}$, \\ Ilya N Nechaev³, Maxim U Shkurnikov³, Alexey E Lebedev' ${ }^{3}$ Irina A Mityakina ${ }^{1,3}$, Andrey D Kaprin³, \\ Udo Schumacher ${ }^{4}$ and Alexander G Tonevitsky ${ }^{2,3^{*}}$
}

\begin{abstract}
Background: Inflammatory breast cancer (IBC) is an extremely malignant form of breast cancer which can be easily misdiagnosed. Conclusive prognostic IBC molecular biomarkers which are also providing the perspectives for targeted therapy are lacking so far. The aim of this study was to reveal the IBC-specific miRNA expression profile and to evaluate its association with clinicopathological parameters.

Methods: miRNA expression profiles of 13 IBC and 17 non-IBC patients were characterized using comprehensive Affymetrix GeneChip miRNA 3.0 microarray platform. Bioinformatic analysis was used to reveal IBC-specific miRNAs, deregulated pathways and potential miRNA targets.

Results: 31 differentially expressed miRNAs characterize IBC and mRNAs regulated by them and their associated pathways can functionally be attributed to IBC progression. In addition, a minimal predictive set of 4 miRNAs characteristic for the IBC phenotype and associated with the TP53 mutational status in breast cancer patients was identified.

Conclusions: We have characterized the complete miRNome of inflammatory breast cancer and found differentially expressed miRNAs which reliably classify the patients to IBC and non-IBC groups. We found that the mRNAs and pathways likely regulated by these miRNAs are highly relevant to cancer progression. Furthermore a minimal IBC-related predictive set of 4 miRNAs associated with the TP53 mutational status and survival for breast cancer patients was identified.
\end{abstract}

Keywords: Inflammatory breast cancer, miRNA, Microarray, tp53 mutational status

\section{Background}

Inflammatory breast cancer (IBC) is an extremely malignant form of breast cancer characterized by early metastases formation and high lethality with the 10 year-survival not exceeding 30\% [1]. For one third of patients distant metastases are already detected within 3 months after first symptoms appeared [2]. As IBC does not produce solid tumors it can easily be misdiagnosed as mastitis or bacterial infection [3]. This makes independent IBC molecular markers having predictive and prognostic value and providing the perspectives for targeted therapy highly desirable.

Today a number of studies on molecular characterization of IBC patient samples have been published including

\footnotetext{
* Correspondence: t.samatov@bioclinicum.com; tonevitsky@mail.ru

'Equal contributors

'SRC Bioclinicum, Ugreshskaya str 2/85, 115088 Moscow, Russia

${ }^{2}$ Moscow State University, Leninskie Gory, 119991 Moscow, Russia

Full list of author information is available at the end of the article
}

several genome-wide transcriptomic analyses [4-9]. However, the suggested mRNA biomarkers differed from one study to another possibly indicating the heterogeneous nature of IBC.

MiRNAs are small non-coding RNAs regulating gene expression which are involved in diverse biological processes [10]. MiRNAs proved to be reliable markers of various diseases including cancers [11]. Recently two pioneering studies have been published discovering miRNA profile of IBC using PCR-based approach [12,13]. Although they have analyzed a limited number of miRNAs and identified completely different profiles, they provided initial insight in the miRNAs regulating RNA networks characteristic for IBC and highlighted the potential of miRNAs as IBC molecular biomarkers.

The aim of the present study was to reveal the complete miRNome and regulated miRNA-mRNA networks of the IBC. Samples from IBC and non-IBC patients analyzed by 
the Affymetrix GeneChip miRNA 3.0 microarray platform formed the basis for this study. Differentially expressed miRNAs and pathways regulated by them were revealed. In addition a minimal predictive set of miRNAs characteristic for IBC phenotype was identified taking clinicopathological parameters of breast cancer patients into consideration.

\section{Methods}

\section{Ethics statement}

The study was approved by the ethics committee of Scientific Research Center Bioclinicum (Moscow, Russia) and all participants signed an informed consent statement.

\section{Patients and material}

Tumor samples were collected from 30 women comprising $13 \mathrm{IBC}$ and 17 non-IBC patients. IBC was diagnosed according to the well-accepted criteria described in the AJCC Cancer Staging Manual [14]. IBC patients presented with diffuse enlargement of the involved breast as well as erythema and oedema of the skin above it. Immediately after surgery the tumor samples were stored in RNAlater buffer (Qiagen, Germany) at $-80^{\circ} \mathrm{C}$ until RNA extraction.

Tumor samples characteristics are presented in Table 1. One patient was assigned to each of IIB, III, IIIC and IV stage subgroups and nine patients were staged as IIIB subgroup within the IBC group whereas non-IBC patients tended to have moderate stages (4 stage I, 1 II, 8 IIA, 1 IIB, 2 IIIA and 1 IIIC). Remarkably $15 \%$ of IBC patients (2 out of 13) had already distant metastases while no metastases were detected among non-IBC group. These data are consistent with the known IBC aggressiveness.

\section{RNA extraction}

Total RNA was extracted from the breast tissue using miRNeasy Mini Kit (Qiagen, Germany) as recommended by the manufacturer. RNA concentrations were determined by the Nanodrop photometer (NanoDrop, USA). RNA quality was checked using the Agilent Bioanalyser 2100 System (Agilent Technologies, USA). For all samples RNA integrity number (RIN) was greater than 7 .

\section{Microarray analysis}

For complete miRNome profiling the samples were prepared using FlashTag Biotin HSR RNA Labeling Kit as recommended by the manufacturer [15]. The samples were hybridized on GeneChip miRNA 3.0 Arrays (Affymetrix) for $16 \mathrm{~h}$ at $48^{\circ} \mathrm{C}$. Arrays were washed to remove nonspecifically bound nucleic acids and stained on Fluidics Station 450 (Affymetrix) and then scanned on GeneChip Scanner 3000 7G system (Affymetrix).
Table 1 Clinico-pathological characteristics of breast cancer samples

\begin{tabular}{|c|c|c|c|}
\hline \multirow[b]{2}{*}{ Characteristics (nb,\%) } & \multicolumn{2}{|c|}{ Breast carcinomas } & \multirow[t]{2}{*}{$p$-value $e^{a, b}$} \\
\hline & $\begin{array}{l}\text { nonIBC } \\
(n=17)\end{array}$ & $\begin{array}{l}\text { IBC } \\
(n=13)\end{array}$ & \\
\hline \multicolumn{4}{|l|}{ Age } \\
\hline Mean \pm SD & $57.4 \pm 12.4$ & $54.4 \pm 13.4$ & $0.27^{\mathrm{a}}$ \\
\hline$\leq 50$ & $5(29 \%)$ & $5(38 \%)$ & $0.71^{b}$ \\
\hline$>50$ & $12(71 \%)$ & $8(62 \%)$ & \\
\hline \multicolumn{4}{|l|}{ Stage } \\
\hline । & $4(24 \%)$ & $0(0 \%)$ & $<0.001^{\mathrm{b}}$ \\
\hline$\|$ & $1(6 \%)$ & $0(0 \%)$ & \\
\hline$\| \mathrm{A}$ & $8(47 \%)$ & $0(0 \%)$ & \\
\hline$\| \mathrm{B}$ & $1(6 \%)$ & $1(8 \%)$ & \\
\hline III & $0(0 \%)$ & $1(8 \%)$ & \\
\hline$\| \mathrm{A}$ & $2(12 \%)$ & $0(0 \%)$ & \\
\hline$\| \mathrm{B}$ & $0(0 \%)$ & $9(69 \%)$ & \\
\hline IIIC & $1(6 \%)$ & $1(8 \%)$ & \\
\hline IV & $0(0 \%)$ & $1(8 \%)$ & \\
\hline \multicolumn{4}{|l|}{ Distant metastates } \\
\hline Yes & $0(0 \%)$ & $2(15 \%)$ & $0.18^{\mathrm{b}}$ \\
\hline No & $17(100 \%)$ & $11(85 \%)$ & \\
\hline \multicolumn{4}{|c|}{ Estrogen receptor status } \\
\hline Positive & $12(71 \%)$ & $5(38 \%)$ & $0.14^{b}$ \\
\hline Negative & $5(29 \%)$ & $8(62 \%)$ & \\
\hline \multicolumn{4}{|c|}{ Progesterone receptor status } \\
\hline Positive & $9(53 \%)$ & $2(15 \%)$ & $0.06^{b}$ \\
\hline Negative & $8(47 \%)$ & $11(85 \%)$ & \\
\hline \multicolumn{4}{|l|}{ HER2 status } \\
\hline Positive & $4(24 \%)$ & $2(15 \%)$ & $0.67^{\mathrm{b}}$ \\
\hline Negative & $13(76 \%)$ & $11(85 \%)$ & \\
\hline \multicolumn{4}{|l|}{ Molecular subtypes } \\
\hline $\mathrm{HR}^{-} \mathrm{HER} 2^{-}$ & $3(18 \%)$ & 7 (54\%) & $0.19^{\mathrm{b}}$ \\
\hline $\mathrm{HR}^{-} \mathrm{HER} 2^{+}$ & $1(6 \%)$ & $1(8 \%)$ & \\
\hline $\mathrm{HR}^{+} \mathrm{HER} 2^{-}$ & $10(59 \%)$ & $4(31 \%)$ & \\
\hline $\mathrm{HR}^{+} \mathrm{HER} 2^{+}$ & $3(18 \%)$ & $1(8 \%)$ & \\
\hline
\end{tabular}

a'Student't test, ${ }^{\text {b } F i s h e r ' s ~ e x a c t ~ t e s t . ~}$

$H R$ : Hormone Receptor; $\mathrm{HR}^{-}$: ER and PR negative; $\mathrm{HR}^{+}$: ER and/or PR positive.

Microarray data processing and bioinformatic analysis GeneChip miRNA 3.0 microarrays were processed using Affymetrix Expression Console (version 1.3.1) [15] implementation of Robust Multichip Average (RMA) method [16]. The processing included background adjustment based on a global model for the distribution of probe intensities [16], quantile normalization [17] and summarization based on Tukey's median polish procedure [18].

The detection of differentially expressed transcripts was restricted to human miRNAs, the signals from all 
other microarray probesets were ignored. The detection of differentially expressed miRNAs was performed using Bioconductor [19] package limma [20]: moderated t-test [21] was applied to log-scaled expression values, and the thresholds were set to 0.01 for the p-value and 1.2 for the fold change.

Hierarchical clusterization for the heatmap (Figure 1) was constructed based on the normalized log-scaled expression values (i.e., log-scaled expression values decreased by the mean value and divided by standard deviation) using Euclidean distance and average cluster method. The construction was performed by the Heatmap online service [22] that utilizes the heatmap tool of $R$ package gplots [23]. For the hierarchical sample clusterization the p-value indicating the association of two resulting clusters with IBC status was obtained using one-sided binomial test. This p-value is the probability of observing the same or better classification accuracy for a classifier

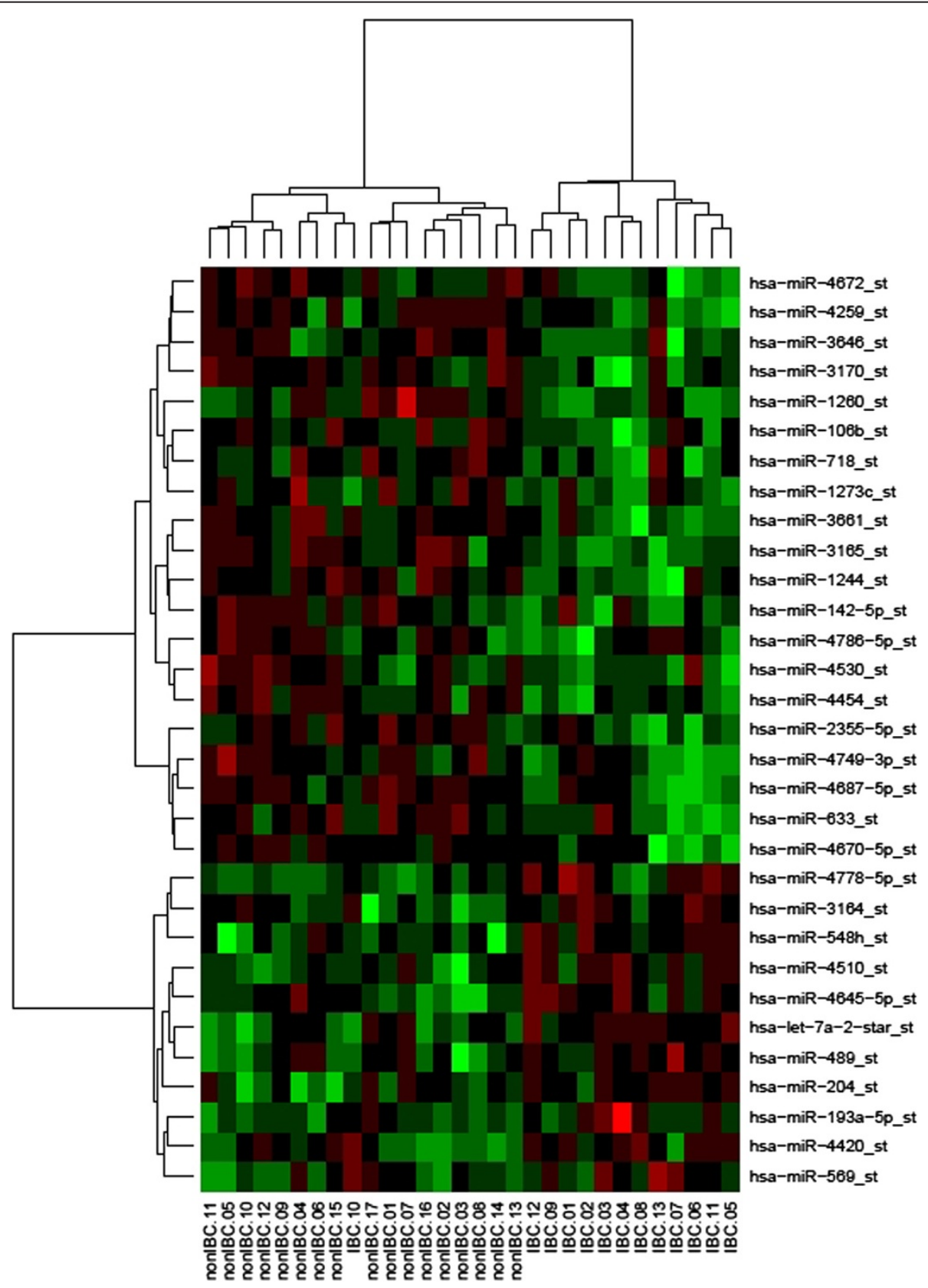

Figure 1 Cluster analysis heatmap for 13 IBC and 17 non-IBC samples based on the expression profile of the 31 differentially expressed miRNAs. The expression data are represented in a 2D format, with rows indicating miRNAs and columns indicating samples. High expression values are coded with red color and low expression values are coded with green. 
with no information rate, i.e., a classifier that attributes a sample to a class with the probability equal to the class percentage in the data.

The validated target mRNAs of differentially expressed miRNAs were found using TARBASE [24], miRecords [25] and miRTarBase [26] databases. The identification of the enriched pathways was performed using DAVID online service $[27,28]$.

The construction of a set of 4 miRNAs for the classification of IBC vs. non-IBC samples was performed using the approach of Galatenko et al. [29]. This approach is based on the Support Vector Machine [30] with linear kernel and greedy-type transcript selection. During the construction the set of the samples was randomly divided into a training set and a testing set. MiRNA log-scaled expressions were normalized using mean expression and standard deviation that were calculated based on the training set. The classifier construction utilized R packages Kernlab [31] and Caret [32].

The assessment of the connection between resulting classifier values and TP53 mutational status for the GSE19536 dataset [33] was performed as follows. The expression values of 4 selected miRNAs were normalized using mean expression and standard deviation that were calculated based on the GSE19536 expression matrix downloaded from the Gene Expression Omnibus data repository. MiRNAs with no expression values were considered to have zero expression and normalized expression was set to zero for these miRNAs. Then classifier values (or, more precisely, values of the linear combination utilized for the classification) were calculated using normalized expression values without any changes in classifier coefficients. Finally, the set of classifier values associated with TP53-mutated samples was compared with the set of classifier values associated with TP53-wild type samples using Mann-Whitney U-test.

\section{Results and discussion}

\section{MiRNA differential expression profile}

The IBC-specific profile of miRNA expression has been identified using comprehensive Affymetrix GeneChip miRNA 3.0 microarray platform. The expression data for 1733 miRNAs are presented in the Additional file 1. 31 miRNAs with the fold change of at least 1.2 times and the p-value not higher than $1 \%$ between non-IBC and IBC groups were considered to be differentially expressed and are listed in the Table 2.

Remarkably, the majority of them are known to be associated with breast cancer, and the up-regulation of highly expressed miRNAs is linked with more aggressive phenotype and poor prognosis. More specifically, hsa-miR-3165, hsa-miR-4687-5p, hsa-miR-3661, hsamiR-4749-3p, hsa-miR-3170, hsa-miR-4672, hsa-miR4670-5p, hsa-miR-4786-5p, and hsa-miR-2355-5p have
Table 2 Differentially expressed miRNAs

\begin{tabular}{|c|c|c|c|}
\hline miRNA & Fold change value & p-value & Adjusted $\mathrm{p}$-value \\
\hline \multicolumn{4}{|c|}{ up-regulated in IBC } \\
\hline hsa-miR-3165 & 1.32 & $2.4 \times 10^{-5}$ & 0.04 \\
\hline hsa-miR-4687-5p & 1.62 & $1.1 \times 10^{-4}$ & 0.06 \\
\hline hsa-miR-4259 & 1.52 & $1.4 \times 10^{-4}$ & 0.06 \\
\hline hsa-miR-3661 & 1.41 & $4.6 \times 10^{-4}$ & 0.15 \\
\hline hsa-miR-4749-3p & 1.57 & $5.1 \times 10^{-4}$ & 0.15 \\
\hline hsa-miR-3170 & 1.31 & $9.2 \times 10^{-4}$ & 0.22 \\
\hline hsa-miR-4672 & 1.53 & $1.1 \times 10^{-3}$ & 0.22 \\
\hline hsa-miR-633 & 1.27 & $1.2 \times 10^{-3}$ & 0.22 \\
\hline hsa-miR-4454 & 1.80 & $1.3 \times 10^{-3}$ & 0.22 \\
\hline hsa-miR-1260 & 1.67 & $1.9 \times 10^{-3}$ & 0.28 \\
\hline hsa-miR-4670-5p & 1.31 & $2.3 \times 10^{-3}$ & 0.30 \\
\hline hsa-miR-718 & 1.76 & $2.4 \times 10^{-3}$ & 0.30 \\
\hline hsa-miR-106b & 1.56 & $2.9 \times 10^{-3}$ & 0.31 \\
\hline hsa-miR-1244 & 2.29 & $3.2 \times 10^{-3}$ & 0.31 \\
\hline hsa-miR-4530 & 1.53 & $5.5 \times 10^{-3}$ & 0.43 \\
\hline hsa-miR-4786-5p & 2.35 & $5.9 \times 10^{-3}$ & 0.43 \\
\hline hsa-miR-3646 & 1.49 & $6.1 \times 10^{-3}$ & 0.43 \\
\hline hsa-miR-142-5p & 1.24 & $7.9 \times 10^{-3}$ & 0.47 \\
\hline hsa-miR-2355-5p & 1.28 & $8.0 \times 10^{-3}$ & 0.47 \\
\hline hsa-miR-1273c & 1.57 & $8.1 \times 10^{-3}$ & 0.47 \\
\hline \multicolumn{4}{|c|}{ down-regulated in IBC } \\
\hline hsa-miR-4778-5p & 1.72 & $7.0 \times 10^{-5}$ & 0.06 \\
\hline hsa-miR-3164 & 1.39 & $1.8 \times 10^{-3}$ & 0.28 \\
\hline hsa-miR-4645-5p & 1.44 & $3.0 \times 10^{-3}$ & 0.31 \\
\hline hsa-miR-4420 & 1.26 & $3.2 \times 10^{-3}$ & 0.31 \\
\hline hsa-miR-4510 & 1.63 & $3.5 \times 10^{-3}$ & 0.32 \\
\hline hsa-miR-548h & 1.24 & $6.1 \times 10^{-3}$ & 0.43 \\
\hline hsa-miR-569 & 1.45 & $6.2 \times 10^{-3}$ & 0.43 \\
\hline hsa-let-7a-2-star & 1.33 & $7.2 \times 10^{-3}$ & 0.47 \\
\hline hsa-miR-204 & 1.45 & $7.3 \times 10^{-3}$ & 0.47 \\
\hline hsa-miR-193a-5p & 1.59 & $9.0 \times 10^{-3}$ & 0.50 \\
\hline hsa-miR-489 & 2.14 & $9.4 \times 10^{-3}$ & 0.51 \\
\hline
\end{tabular}

The miRNAs with $p$-value $<0.01$ and fold change $>1.5$ are marked with bold.

been detected in breast cancer when compared with normal breast tissue [34]. Circulating hsa-miR-718 was suggested to be a fluid biomarker for breast cancer [35]. Expression of hsa-miR-106b is elevated in higher stage tumors and correlated with tumor progression [36]. Hsa-miR-142-5p has been demonstrated to be upregulated in lymph node breast cancer patients [37].

Other up-regulated miRNAs have been associated with different types of malignomas including hsa-miR-1260 and hsa-miR-1273c for melanoma [38], hsa-miR-633 for endometrial cancer [39], hsa-miR-1244 for hepatocellular 
carcinoma [40], hsa-miR-4454 and hsa-miR-4530 for malignant B cells [41].

The miRNAs down-regulated in IBC group include hsa-miR-204 which has been characterized as a tumor suppressor in breast cancer [42], ovarian cancers and pediatric renal tumors [43]. Hsa-miR-193a-5p is also less expressed in IBC patients and is known to play a suppressive role in breast cancer [44]. Another down-regulated miRNA is hsa-miR-489 targeting Smad3 transcription factor thus inhibiting epithelial-mesenchymal transition of breast cancer cells which prevents metastases formation and makes the cells more susceptible to chemotherapy [45]. The let-7 family of miRNAs is reduced in rare selfrenewing breast tumor-initiating cells [46].

Consistent with the expression level of the above listed miRNAs, down-regulated hsa-miR-548h is more abundant in normal lung tissue than in lung cancer [47], and hsa-let-7a-2 is less expressed in aggressive hepatocellular carcinoma [48] and its down-regulation is correlated with poor survival in lung cancer [49].

The hierarchical clustering of breast cancer samples according to the differentially expressed miRNAs is presented in Figure 1. Remarkably, the patients were indeed separated into non-IBC and IBC clusters with the only one IBC sample misclassified resulting in the p-value of $9.5 \times 10^{-7}$.

All these data are consistent with the more aggressive nature of IBC and suggest the differentially expressed miRNAs to be molecular biomarkers for IBC. Notably, the revealed miRNA pattern does not overlap with the previously identified profiles [12,13]. This can be explained by the larger number of miRNAs covered by the comprehensive microarrays used in this study as compared to both previous studies.

During IBC progression breast tumors are infiltrated by inflammatory cells, in particular monocytes/macrophages [50,51]. We checked miRNA profile of these cells which has been recently published [52]. Only 6 out of 20 up-regulated in IBC miRNAs are pronouncedly expressed in macrophages, namely hsa-miR-142-5p, hsa-miR-106b, hsa-miR-4454, hsa-miR-2355-5p, has-miR-1273c and hsamiR-4687-5p (Table 2). This moderate intersection clearly indicates that the identified miRNA profile is indeed IBCspecific and cannot be due to the migrated macrophages.

\section{mRNA targets of differentially expressed miRNAs}

The mRNAs which have been validated to be targets for the differentially expressed miRNAs were found using online databases as described in Methods. All 31 differentially expressed miRNAs have 428 target mRNAs in total. We performed pathway enrichment analysis for these genes (Table 3). The top of revealed pathways includes phosphoproteins, regulation of kinase activity and cell proliferation all known to be highly relevant to
Table 3 Selected pathways highly enriched with the validated target genes of differentially expressed miRNAs

\begin{tabular}{lll}
\hline Pathway & Number of genes & Adjusted P-value \\
\hline Phosphoprotein & 256 & $2.3 \times 10^{-18}$ \\
Acetylation & 127 & $8.0 \times 10^{-17}$ \\
Transcription & 86 & $1.4 \times 10^{-6}$ \\
Regulation of kinase activity & 28 & $4.6 \times 10^{-4}$ \\
DNA binding & 100 & $4.6 \times 10^{-4}$ \\
Regulation of cell proliferation & 45 & $6.9 \times 10^{-4}$ \\
Protein biosynthesis & 17 & $2.3 \times 10^{-4}$ \\
\hline
\end{tabular}

malignant progression. Besides, acetylation, transcription, DNA binding and protein biosynthesis are the key interrelated steps in gene expression and their deregulation is involved in cancer progression [53].

The same mRNA can be targeted by more than one miRNA thus providing for more efficient and specific regulation [54]. Table 4 lists the mRNAs regulated by 2 differentially expressed miRNAs. These 11 mRNAs are more likely involved in the IBC progression.

More specifically, amyloid beta precursor-like protein 2 (APLP2) is targeted by hsa-miR-106b and hsa-miR1260. These miRNAs are up-regulated in IBC thus potentially suppressing the expression of this gene. Notably, hsa-miR-106b and hsa-miR-1260 follow the more stringent criteria in t-test, namely p-value $<0.01$ and fold change $>1.5$, supporting their functional relevance. Remarkably, APLP2 mRNA is known to be downregulated in neuroendocrine tumors and lung cancer $[55,56]$. The same two miRNAs target amyloid beta precursor protein (APP) which has been identified as a hub protein in differentially expressed networks between ER+ and ER- breast cancer patients [57]. Another target of these miRNAs is cyclin-dependent kinase inhibitor 1A (CDKN1A). Low expression of this gene in breast cancer

Table 4 mRNAs targeted with 2 differentially expressed miRNAs

\begin{tabular}{ll}
\hline miRNAs & Validated target genes \\
\hline hsa-miR-106b $\uparrow$ & APLP2, APP, CDKN1A, EEF1A1, PRMT3 \\
hsa-miR-1260 $\uparrow$ & ELOVL6, IPO7 \\
hsa-miR-106b $\uparrow$ & \\
hsa-miR-204 & ENO1, RPL3 \\
hsa-miR-1260 $\uparrow$ & \\
hsa-miR-204 & HMGA2 \\
hsa-let-7a-2-star $\downarrow$ & \\
hsa-miR-204 $\downarrow$ & VEGFA \\
hsa-miR-106b $\uparrow$ & \\
hsa-miR-548 h $\downarrow$ & \\
\hline Up- and down-regulated miRNAs in IBC vs, non-IBC patients are indicated by
\end{tabular}

Up- and down-regulated miRNAs in IBC vs. non-IBC patients are indicated by the upward and downward arrows, respectively. 
patients is associated with poor survival after chemotherapy which is consistent with the aggressiveness of IBC [58]. Hsa-miR-106b and hsa-miR-1260 also regulate alpha 1 subunit of eukaryotic translation elongation factor 1 (EEF1A1). This protein is involved in regulation of epithelial-mesenchymal transition in breast cancer cells [59]. At the same time EEF1A1 has been identified as a reliable reference gene for quantitative PCR assay of breast cancer patient biopsies, i.e. this mRNA is equally abundant across multiple breast cancer samples [60]. Finally these two miRNAs target protein arginine methyltransferase 3 (PRMT3) mRNA, an enzyme interacting with DAL-1/4.1B protein thus inducing apoptosis in breast cancer cells [61].

Fatty acid elongase 6 (ELOVL6) is targeted by hsamiR-106b and hsa-miR-204. The expression of these miRNAs is changed in opposite directions implying balanced and delicate regulation of the target mRNA. The functional link of this rate-limiting enzyme of de novo lipogenesis to the breast tumorigenesis has been revealed using mouse models [62]. The expression of the protein of nuclear import importin 7 (IPO7) is also regulated by these oppositely directed miRNAs. This protein is known to be involved in the regulation of prostate cancer cells proliferation [63]. Additionally the importin 7-mediated nuclear import plays an important role in the keratin 19 tumor suppressor mechanism in breast cancer cells [64].

The mRNA of enolase 1 (ENO1) is targeted by both up-regulated hsa-miR-1260 and down-regulated hsamiR-204. The increased level of this protein is associated with a poor prognosis for breast cancer patients and involved in tamoxifen and methotrexate resistance of breast cancer cells $[65,66]$. Another target of these miRNAs is the gene RPL3 coding for the ribosomal protein L3. This protein is a member of the Pes1-Bop1 complex involved in the colorectal tumorigenesis [67].

The decreased in IBC patients hsa-let-7a-2-star and hsamiR-204 are expected to increase the level of the transcriptional regulator high mobility group AT-hook protein 2 encoded by the HMGA2 gene. Remarkably, the rare self-renewing breast tumor-initiating cells have been described to contain more of HMGA2 mRNA in combination with reducing of its regulator hsa-let-7a-2-star [46]. Also recently the overexpression of this gene was found to make the breast cancer cells more metastatic [68,69].

Finally the VEGFA mRNA is targeted by the oppositely directed hsa-miR-106b and hsa-miR-548 h. This gene encodes vascular endothelial growth factor A, a protein with well-established role in cancer progression. Its increased expression is associated with loss of wild type tp53 status and predicts poor outcome for the breast cancer patients [70] which can functionally be explained by the induction of angio- and lymphangiogenesis [71].
Recently an angiogenesis-independent function of VEGFA has been reported, namely the protein produced by tumor cells can act in an autocrine manner to promote cell growth, and reducing its expression resulted in a differentiated phenotype in vitro and inhibited tumor forming capacity in vivo [72].

The presented data support the functional relevance of the revealed miRNA-mRNA networks to the IBC progression and denote potential targets for the IBC-specific therapy.

\section{A predictive set of 4 miRNAs associated with TP53 mutation status}

As IBC is characterized by high aggressiveness and poor survival we tried to identify a minimal set of miRNAs which could reliably classify patients to IBC or non-IBC group and have overall predictive value for breast cancer patients. We have investigated sets of 4 miRNAs using a bioinformatic approach based on the Support Vector Machine [30] with linear kernel and greedy-type transcript selection as described in Methods. The collection of the samples was randomly divided into a training set and a testing set. The classifier was constructed based solely on the training set which contained 7 IBC and 9 non-IBC samples. It used the expression values of hsalet-7a, hsa-miR-582-5p, hsa-miR-591 and hsa-mir-16-2$3 p$ as follows. Normalized log-scaled expression values of these miRNAs were combined in a linear combination with weights of $-1.73,1.36,-0.57$, and -0.56 , respectively. Then the value of this linear combination was compared with a threshold of 0.49 , namely the higher values attributed a sample to IBC class and the lower values attributed a sample to non-IBC class. This means that the sample classification performed by this classifier is based on the value of the linear combination:

$$
\begin{aligned}
L= & -1.73 \text { Expr }_{\text {let }-7 a} \\
& +1.36 \text { Expr }_{\text {miR-582-5p }}-0.57 E x p r_{\text {miR-591 }} \\
& -0.56 E x p r_{\text {miR-16-2-3p }}-0.49
\end{aligned}
$$

where Expr is a normalized log-scaled expression of the corresponding miRNA for the sample, and positive values of $L$ attribute a sample to the IBC class while negative values of $L$ attribute a sample to a non-IBC class. In case of the training set this classifier successfully classified 14 samples and 2 IBC samples were misclassified as belonging to non-IBC class resulting in the accuracy of $87.5 \%$. For the testing set comprising 6 IBC and 8 non-IBC samples only one sample was misclassified (a non-IBC sample was attributed to IBC class), and hence the resulting accuracy was $92.9 \%$. The fact that miRNAs from the identified predictive set are not differentially expressed is due to the used algorithm which is aimed at the maximization of a cumulative informative 
power of a miRNA set irrespectively of the individual informative power of selected miRNAs.

We hypothesized that the identified set of 4 miRNAs could be associated with clinico-pathological characteristics of breast cancer patients in general. To test this hypothesis we used published miRNA dataset of 101 breast cancer patient collection with GEO accession number GSE19783 [33]. The analysis revealed significant association of miRNA set with the TP53 mutational status characterized by the p-value of $1.7 \times 10^{-4}$ (Figure 2). The dataset included 64 wild-type TP53 samples and 37 samples with mutated TP53.

The tumor suppressor gene TP53 encodes a transcription factor which possesses multiple functions. It has been reported to often have missense mutations in many cancers compromising its suppressor function. Although current experimental data on the acquisition of oncogenic activities by the mutant forms of this protein are too heterogenous to directly conclude about its impact on tumor development and outcome, TP53 is considered to be an important prognostic marker [73]. In combination with other parameters, e.g., expression profile of selected genes, TP53 mutational status can provide the information on the overall survival and response to treatment for breast cancer patients [74].

Figure 3 demonstrates overall survival of the patients from the dataset GSE19783 classified using the same IBCspecific set of 4 miRNAs. The patients with the expression pattern characteristic for IBC have poor prognosis (blue curve) whereas the non-IBC-like patients have better

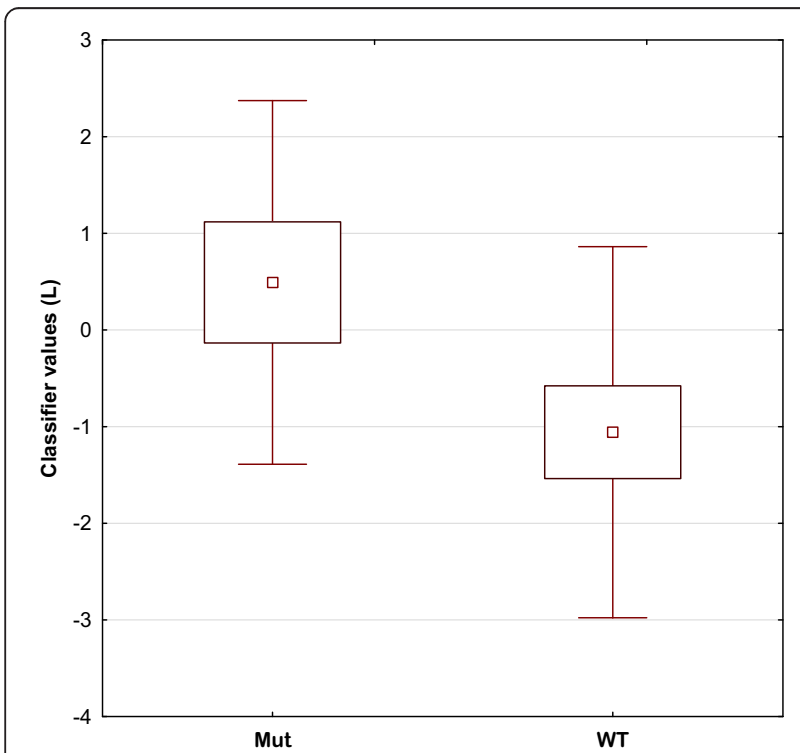

Figure 2 Association of a predictive set of 4 miRNAs with the TP53 mutational status. Classifier values $L$ for TP53-mutated (Mut) and TP53 wild-type (WT) samples. Smaller bar shows the estimate of the mean value, larger bar shows a 95\% confidence interval for the mean value. Vertical line shows mean value \pm standard deviation.

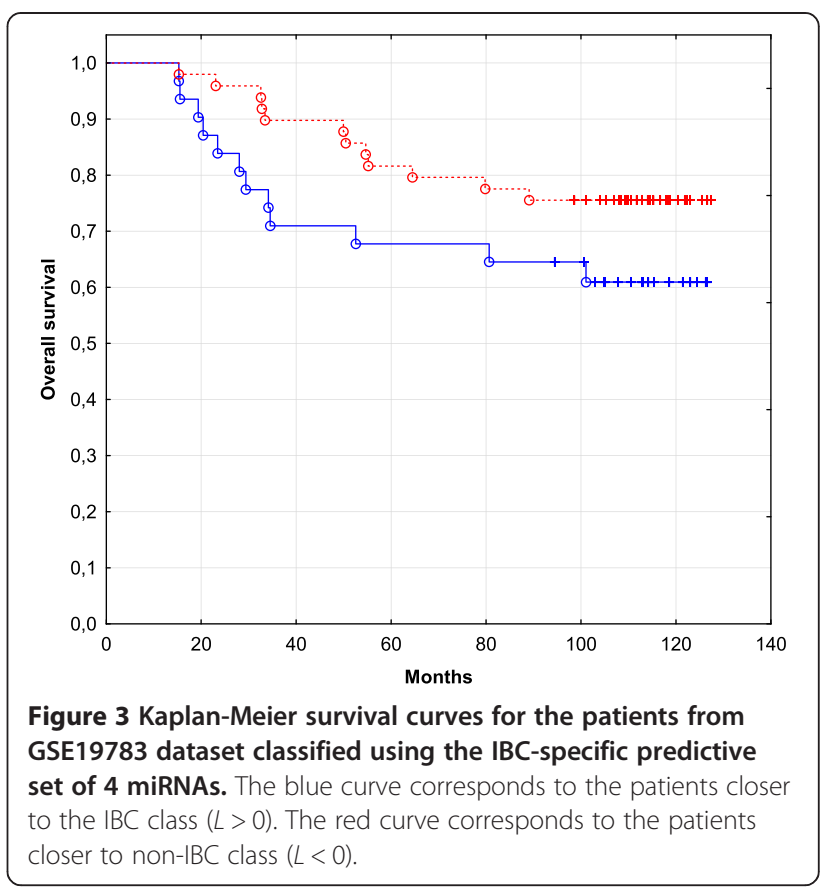

survival (red curve). Although the Cox F-test p-value is only $7.3 \%$ here indicating moderate statistical significance, the result is consistent with the clinical value of TP53 status and points out to the functional relevance of IBC-specific miRNA expression pattern.

\section{Conclusions}

We have characterized the complete miRNome of inflammatory breast cancer and revealed differentially expressed miRNAs which reliably classify the patients to IBC and non-IBC groups. We found that the mRNAs and pathways likely regulated by these miRNAs are highly relevant to cancer progression. Also we identified a minimal IBC-related predictive set of 4 miRNAs associated with the TP53 mutational status and survival for breast cancer patients. The described miRNAs should be investigated in future as potential biomarkers and targets for therapy.

\section{Additional file}

Additional file 1: miRNA expression data of the patients.

\section{Abbreviations}

miRNA: microRNA; mRNA: Messenger RNA; IBC: Inflammatory breast cancer.

\section{Competing interests}

The authors declare that they have no competing interests.

\section{Authors' contributions}

Conception and design of the experiments: AGT, DVM, MUS, ADK. Collection, analysis and interpretation of data: DVM, WG, SOZ, NAK, INN, MUS, AEL, IAM, TRS. Drafting the article and revising it critically TRS, AGT, US. All authors read and approved the final manuscript. 


\section{Acknowledgements}

We thank Drs Nikita Savelov, Vyacheslav Grinevich and Erik Saribekyan for providing the samples and Daniil Maximenko for technical assistance. This work was supported by the Russian Ministry of Science Grant 14.579.21.0054.

\section{Author details}

${ }^{1}$ SRC Bioclinicum, Ugreshskaya str 2/85, 115088 Moscow, Russia. ${ }^{2}$ Moscow State University, Leninskie Gory, 119991 Moscow, Russia. ${ }^{3}$ P.A. Hertsen Moscow Research Oncology Institute, 2nd Botkinskii p. 3, Moscow 125284, Russia. ${ }^{4}$ Department of Anatomy and Experimental Morphology, University Cancer Center, University Medical Center Hamburg-Eppendorf, Martinistr. 52, Hamburg D-20246, Germany.

Received: 26 August 2014 Accepted: 28 November 2014

Published: 4 December 2014

\section{References}

1. Hance KW, Anderson WF, Devesa SS, Young HA, Levine PH: Trends in inflammatory breast carcinoma incidence and survival: the surveillance, epidemiology, and end results program at the National Cancer Institute. J Natl Cancer Inst 2005, 97:966-975.

2. Yamauchi H, Woodward WA, Valero V, Alvarez RH, Lucci A, Buchholz TA, Iwamoto T, Krishnamurthy S, Yang W, Reuben JM, Hortobágyi GN, Ueno NT: Inflammatory breast cancer: what we know and what we need to learn. Oncologist 2012, 17:891-899.

3. Boutet $\mathrm{G}$ : Breast inflammation: clinical examination, aetiological pointers. Diagn Interv Imaging 2012, 93:78-84.

4. Bertucci F, Finetti P, Rougemont J, Charafe-Jauffret E, Nasser V, Loriod B, Camerlo J, Tagett R, Tarpin C, Houvenaeghel G, Nguyen C, Maraninchi D, Jacquemier J, Houlgatte R, Birnbaum D, Viens P: Gene expression profiling for molecular characterization of inflammatory breast cancer and prediction of response to chemotherapy. Cancer Res 2004, 64:8558-8565.

5. Van Laere S, Van der Auwera I, Van den Eynden G, Van Hummelen P, van Dam P, Van Marck E, Vermeulen PB, Dirix L: Distinct molecular phenotype of inflammatory breast cancer compared to non-inflammatory breast cancer using Affymetrix-based genome-wide gene-expression analysis. Br J Cancer 2007, 97:1165-1174

6. Van Laere S, Beissbarth T, Van der Auwera I, Van den Eynden G, Trinh XB, Elst $H$, Van Hummelen P, van Dam P, Van Marck E, Vermeulen P, Dirix L: Relapse-free survival in breast cancer patients is associated with a gene expression signature characteristic for inflammatory breast cancer. Clin Cancer Res 2008, 14:7452-7460.

7. Iwamoto T, Bianchini G, Qi Y, Cristofanilli M, Lucci A, Woodward WA, Reuben JM, Matsuoka J, Gong Y, Krishnamurthy S, Valero V, Hortobagyi GN, Robertson F, Symmans WF, Pusztai L, Ueno NT: Different gene expressions are associated with the different molecular subtypes of inflammatory breast cancer. Breast Cancer Res Treat 2011, 125:785-795.

8. Shkurnikov MY, Nechaev IN, Khaustova NA, Krainova NA, Savelov NA Grinevich VN, Saribekyan EK: Expression profile of inflammatory breast cancer. Bull Exp Biol Med 2013, 155:667-672.

9. Van Laere SJ, Ueno NT, Finetti P, Vermeulen P, Lucci A, Robertson FM, Marsan M, Iwamoto T, Krishnamurthy S, Masuda H, van Dam P, Woodward WA, Viens P, Cristofanilli M, Birnbaum D, Dirix L, Reuben JM, Bertucci F: Uncovering the molecular secrets of inflammatory breast cancer biology: an integrated analysis of three distinct affymetrix gene expression datasets. Clin Cancer Res 2013, 19:4685-4696.

10. Turchinovich A, Samatov TR, Tonevitsky AG, Burwinkel B: Circulating miRNAs: cell-cell communication function? Front Genet 2013, 4:119.

11. Calin GA, Croce CM: MicroRNA signatures in human cancers. Nat Rev Cancer 2006, 6:857-866.

12. Van der Auwera I, Limame $R$, van Dam P, Vermeulen PB, Dirix LY, Van Laere SJ: Integrated miRNA and mRNA expression profiling of the inflammatory breast cancer subtype. Br J Cancer 2010, 103:532-541.

13. Lerebours F, Cizeron-Clairac G, Susini A, Vacher S, Mouret-Fourme E, Belichard C, Brain E, Alberini JL, Spyratos F, Lidereau R, Bieche I: miRNA expression profiling of inflammatory breast cancer identifies a 5-miRNA signature predictive of breast tumor aggressiveness. Int J Cancer 2013, 133:1614-1623.

14. Edge S, Byrd DR, Compton CC, Fritz AG, Greene FL, Trotti A: AJCC Cancer Staging Manual. 7th edition. New York, NY: Springer; 2010.
15. Affymetrix ${ }^{\oplus}$ Expression Console ${ }^{\top m}$ Software 1.4 User Manual. @Affymetrix, Inc. 2014, [http://media.affymetrix.com/support/downloads/manuals/ expression_console_userguide.pdf]

16. Irizarry RA, Hobbs B, Collin F, Beazer-Barclay YD, Antonellis KJ, Scherf U, Speed TP: Exploration, normalization, and summaries of high density oligonucleotide array probe level data. Biostatistics 2003, 4:249-264.

17. Bolstad BM, Irizarry RA, Astrand M, Speed TP: A comparison of normalization methods for high density oligonucleotide array data based on variance and bias. Bioinformatics 2003, 19:185-193.

18. Tukey JW: Exploratory data analysis. Reading: Addison-Wesley; 1977.

19. Gentleman RC, Carey VJ, Bates DM, Bolstad B, Dettling M, Dudoit S, Ellis B, Gautier L, Ge Y, Gentry J, Hornik K, Hothorn T, Huber W, lacus S, Irizarry R, Leisch F, Li C, Maechler M, Rossini AJ, Sawitzki G, Smith C, Smyth G, Tierney $L$, Yang JY, Zhang J: Bioconductor: open software development for computational biology and bioinformatics. Genome Biol 2004, 5:R80.

20. Smyth GK: Limma: linear models for microarray data. In Bioinformatics and Computational Biology Solutions Using R and Bioconductor. Edited by Gentleman R, Carey V, Dudoit S, Irizarry R, Huber W. New York: Springer; 2005:397-420

21. Smyth GK: Linear models and empirical Bayes methods for assessing differential expression in microarray experiments. Stat Appl Genet Mol Biol 2004, 3:Article 3.

22. Los Alamos National Security, LLC: Heatmap Online Service. 2013, [http://www.hiv.lanl.gov/content/sequence/HEATMAP/heatmap.html]

23. Warnes GR, Bolker B, Bonebakker L, Gentleman R, Huber W, Liaw A, Lumley T, Maechler M, Magnusson A, Moeller S, Schwartz M, Venables B: R package gplots. 2014, [http://cran.r-project.org/web/packages/gplots/gplots.pdf]

24. Vergoulis T, Vlachos IS, Alexiou P, Georgakilas G, Maragkakis M, Reczko M, Gerangelos S, Koziris N, Dalamagas T, Hatzigeorgiou AG: TarBase 6.0: capturing the exponential growth of miRNA targets with experimental support. Nucleic Acids Res 2012, 40:D222-229.

25. Xiao F, Zuo Z, Cai G, Kang S, Gao X, Li T: miRecords: an integrated resource for microRNA-target interactions. Nucleic Acids Res 2009, 37:D105-110.

26. Hsu SD, Tseng YT, Shrestha S, Lin YL, Khaleel A, Chou CH, Chu CF, Huang HY, Lin CM, Ho SY, Jian TY, Lin FM, Chang TH, Weng SL, Liao KW, Liao IE, Liu CC, Huang HD: miRTarBase update 2014: an information resource for experimentally validated miRNA-target interactions. Nucleic Acids Res 2014, 42:D78-D85.

27. Huang DW, Sherman BT, Lempicki RA: Systematic and integrative analysis of large gene lists using DAVID Bioinformatics Resources. Nat Protoc 2009, 4:44-57.

28. Huang DW, Sherman BT, Lempicki RA: Bioinformatics enrichment tools: paths toward the comprehensive functional analysis of large gene lists. Nucleic Acids Res 2009, 37:1-13.

29. Galatenko W, Lebedev AE, Nechaev IN, Shkurnikov MY, Tonevitskii EA, Podol'skii VE: On the construction of medical test systems using greedy algorithm and support vector machine. Bull Exp Biol Med 2014, 156:706-709.

30. Cortes C, Vapnik V: Support-vector networks. Machine Learning 1995, 20:273-297

31. Karatzoglou A, Smola A, Hornik K, Zeileis A: kernlab - An S4 Package for Kernel Methods in R. J Stat Software 2004, 11:1-20.

32. Kuhn M: R package Caret. 2014, [http://cran.r-project.org/web/packages/ caret/caret.pdf]

33. Enerly E, Steinfeld I, Kleivi K, Leivonen SK, Aure MR, Russnes HG, Rønneberg JA, Johnsen H, Navon R, Rødland E, Mäkelä R, Naume B, Perälä M, Kallioniemi O, Kristensen VN, Yakhini Z, Børresen-Dale AL: miRNA-mRNA integrated analysis reveals roles for miRNAs in primary breast tumors. PLoS One 2011, 6:e16915.

34. Persson H, Kvist A, Rego N, Staaf J, Vallon-Christersson J, Luts L, Loman N, Jonsson G, Naya H, Hoglund M, Borg A, Rovira C: Identification of new microRNAs in paired normal and tumor breast tissue suggests a dual role for the ERBB2/Her2 gene. Cancer Res 2011, 71:78-86.

35. Schrauder MG, Strick R, Schulz-Wendtland R, Strissel PL, Kahmann L, Loehberg CR, Lux MP, Jud SM, Hartmann A, Hein A, Bayer CM, Bani MR, Richter S, Adamietz BR, Wenkel E, Rauh C, Beckmann MW, Fasching PA: Circulating micro-RNAs as potential blood-based markers for early stage breast cancer detection. PLoS One 2012, 7:e29770.

36. Gong C, Qu S, Liu B, Pan S, Jiao Y, Nie Y, Su F, Liu Q, Song E: MiR-106b expression determines the proliferation paradox of TGF- $\beta$ in breast cancer cells. Oncogene 2013, 10.1038/onc.2013.525. 
37. Wang B, Li J, Sun M, Sun L, Zhang X: MiRNA expression in breast cancer varies with lymph node metastasis and other clinicopathologic features. IUBMB Life 2014, 10.1002/iub.1273.

38. Sand M, Skrygan M, Sand D, Georgas D, Gambichler T, Hahn SA, Altmeyer P, Bechara FG: Comparative microarray analysis of microRNA expression profiles in primary cutaneous malignant melanoma, cutaneous malignant melanoma metastases, and benign melanocytic nevi. Cell Tissue Res 2013, 351:85-98.

39. Bae J, Won M, Kim DY, Kim JH, Kim YM, Kim YT, Nam JH, Suh DS: Identification of differentially expressed microRNAs in endometrial cancer cells after progesterone treatment. Int J Gynecol Cancer 2012, 22:561-565.

40. Zha R, Guo W, Zhang Z, Qiu Z, Wang Q, Ding J, Huang S, Chen T, Gu J, Yao M, He X: Genome-wide screening identified that miR-134 acts as a metastasis suppressor by targeting integrin $\beta 1$ in hepatocellular carcinoma. PLoS One 2014, 9:e87665

41. Jima DD, Zhang J, Jacobs C, Richards KL, Dunphy CH, Choi WW, Au WY, Srivastava G, Czader MB, Rizzieri DA, Lagoo AS, Lugar PL, Mann KP, Flowers CR, Bernal-Mizrachi L, Naresh KN, Evens AM, Gordon LI, Luftig M, Friedman DR, Weinberg JB, Thompson MA, Gill JI, Liu Q, How T, Grubor V, Gao Y, Patel A, Wu H, Zhu J, et al: Hematologic Malignancies Research Consortium. Deep sequencing of the small RNA transcriptome of normal and malignant human B cells identifies hundreds of novel microRNAs. Blood 2010, 116:e118-127.

42. Vimalraj S, Miranda PJ, Ramyakrishna B, Selvamurugan N: Regulation of breast cancer and bone metastasis by microRNAs. Dis Markers 2013, 35:369-387.

43. Imam JS, Plyler JR, Bansal H, Prajapati S, Bansal S, Rebeles J, Chen HI, Chang YF, Panneerdoss S, Zoghi B, Buddavarapu KC, Broaddus R, Hornsby P, Tomlinson G, Dome J, Vadlamudi RK, Pertsemlidis A, Chen Y, Rao MK: Genomic loss of tumor suppressor miRNA-204 promotes cancer cell migration and invasion by activating AKT/mTOR/Rac1 signaling and actin reorganization. PLoS One 2012, 7:e52397.

44. Tahiri A, Leivonen SK, Lüders T, Steinfeld I, Ragle Aure M, Geisler J, Mäkelä R, Nord S, Riis ML, Yakhini Z, Kleivi Sahlberg K, Børresen-Dale AL, Perälä M, Bukholm IR, Kristensen VN: Deregulation of cancer-related miRNAs is a common event in both benign and malignant human breast tumors. Carcinogenesis 2014, 35:76-85.

45. Jiang L, He D, Yang D, Chen Z, Pan Q, Mao A, Cai Y, Li X, Xing H, Shi M, Chen Y, Bruce IC, Wang T, Jin L, Qi X, Hua D, Jin J, Ma X: MiR-489 regulates chemoresistance in breast cancer via epithelial mesenchymal transition pathway. FEBS Lett 2014, 588:2009-2015.

46. Yu F, Yao H, Zhu P, Zhang X, Pan Q, Gong C, Huang Y, Hu X, Su F, Lieberman J: let-7 regulates self renewal and tumorigenicity of breast cancer cells. Cell 2007, 131:1109-1123.

47. Hu B, Ying X, Wang J, Piriyapongsa J, Jordan IK, Sheng J, Yu F, Zhao P, Li Y, Wang $H$, Ng WL, Hu S, Wang X, Wang C, Zheng X, Li W, Curran WJ, Wang Y: Identification of a tumor-suppressive human-specific microRNA within the FHIT tumor-suppressor gene. Cancer Res 2014, 74:2283-2294.

48. Cairo S, Wang Y, de Reyniès A, Duroure K, Dahan J, Redon MJ, Fabre M, McClelland M, Wang XW, Croce CM, Buendia MA: Stem cell-like micro-RNA signature driven by Myc in aggressive liver cancer. Proc Natl Acad Sci U S A 2010, 107:20471-20476.

49. Yanaihara N, Caplen N, Bowman E, Seike M, Kumamoto K, Yi M, Stephens RM, Okamoto A, Yokota J, Tanaka T, Calin GA, Liu CG, Croce CM, Harris CC: Unique microRNA molecular profiles in lung cancer diagnosis and prognosis. Cancer Cell 2006, 9:189-198.

50. Pollard JW: Macrophages define the invasive microenvironment in breast cancer. J Leukoc Biol 2008, 84:623-630.

51. Mohamed MM, El-Ghonaimy EA, Nouh MA, Schneider RJ, Sloane BF, ElShinawi M: Cytokines secreted by macrophages isolated from tumor microenvironment of inflammatory breast cancer patients possess chemotactic properties. Int J Biochem Cell Biol 2014, 46:138-147.

52. Cobos Jiménez V, Bradley EJ, Willemsen AM, van Kampen AH, Baas F, Kootstra NA: Next-generation sequencing of microRNAs uncovers expression signatures in polarized macrophages. Physiol Genomics 2014, 46:91-103.

53. Alberts B, Johnson A, Lewis J, Raff M: Molecular Biology of the Cell. 5th edition. New York, NY: Garland Science; 2007

54. Broderick JA, Salomon WE, Ryder SP, Aronin N, Zamore PD: Argonaute protein identity and pairing geometry determine cooperativity in mammalian RNA silencing. RNA 2011, 17:1858-1869.
55. Arvidsson $Y$, Andersson E, Bergström A, Andersson MK, Altiparmak G, Illerskog AC, AhIman H, Lamazhapova D, Nilsson O: Amyloid precursor-like protein 1 is differentially upregulated in neuroendocrine tumours of the gastrointestinal tract. Endocr Relat Cancer 2008, 15:569-581

56. Srivastava $M$, Khurana $P$, Sugadev R: Lung cancer signature biomarkers: tissue specific semantic similarity based clustering of digital differential display (DDD) data. BMC Res Notes 2012, 5:617.

57. Ma W, Zhang TF, Lu P, Lu SH: Partial least squares based gene expression analysis in estrogen receptor positive and negative breast tumors. Eur Rev Med Pharmacol Sci 2014, 18:212-216.

58. Somlo G, Chu P, Frankel P, Ye W, Groshen S, Doroshow JH, Danenberg K Danenberg P: Molecular profiling including epidermal growth factor receptor and p21 expression in high-risk breast cancer patients as indicators of outcome. Ann Oncol 2008, 19:1853-1859.

59. Hussey GS, Chaudhury A, Dawson AE, Lindner DJ, Knudsen CR, Wilce MC, Merrick WC, Howe PH: Identification of an mRNP complex regulating tumorigenesis at the translational elongation step. Mol Cell 2011, 41:419-431.

60. Maltseva DV, Khaustova NA, Fedotov NN, Matveeva EO, Lebedev AE, Shkurnikov MU, Galatenko W, Schumacher U, Tonevitsky AG: High-throughput identification of reference genes for research and clinical RT-qPCR analysis of breast cancer samples. J Clin Bioinforma 2013, 3:13.

61. Jiang W, Newsham IF: The tumor suppressor DAL-1/4.1B and protein methylation cooperate in inducing apoptosis in MCF-7 breast cancer cells. Mol Cancer 2006, 5:4

62. Khaidakov M, Mitra S, Kang BY, Wang X, Kadlubar S, Novelli G, Raj V Winters M, Carter WC, Mehta JL: Oxidized LDL receptor 1 (OLR1) as a possible link between obesity, dyslipidemia and cancer. PLoS One 2011, 6:e20277.

63. Szczyrba J, Nolte E, Hart M, Döll C, Wach S, Taubert H, Keck B, Kremmer E, Stöhr R, Hartmann A, Wieland W, Wullich B, Grässer FA: Identification of ZNF217, hnRNP-K, VEGF-A and IPO7 as targets for microRNAs that are downregulated in prostate carcinoma. Int J Cancer 2013, 132:775-784.

64. Ju JH, Yang W, Lee KM, Oh S, Nam K, Shim S, Shin SY, Gye MC, Chu IS, Shin I: Regulation of cell proliferation and migration by keratin19-induced nuclear import of early growth response- 1 in breast cancer cells. Clin Cancer Res 2013, 19:4335-4346.

65. Tu SH, Chang CC, Chen CS, Tam KW, Wang YJ, Lee CH, Lin HW, Cheng TC, Huang CS, Chu JS, Shih NY, Chen LC, Leu SJ, Ho YS, Wu CH: Increased expression of enolase alpha in human breast cancer confers tamoxifen resistance in human breast cancer cells. Breast Cancer Res Treat 2010, 121:539-553.

66. Chen S, Cai J, Zhang W, Zheng X, Hu S, Lu J, Xing J, Dong Y: Proteomic identification of differentially expressed proteins associated with the multiple drug resistance in methotrexate-resistant human breast cancer cells. Int J Oncol 2014, 45:448-458.

67. Killian A, Sarafan-Vasseur N, Sesboüé R, Le Pessot F, Blanchard F, Lamy A, Laurent M, Flaman JM, Frébourg T: Contribution of the BOP1 gene, located on $8 q 24$, to colorectal tumorigenesis. Genes Chromosomes Cancer 2006, 45:874-881.

68. Morishita A, Zaidi MR, Mitoro A, Sankarasharma D, Szabolcs M, Okada Y, D'Armiento J, Chada K: HMGA2 is a driver of tumor metastasis. Cancer Res 2013, 73:4289-4299.

69. Sun M, Song CX, Huang H, Frankenberger CA, Sankarasharma D, Gomes S, Chen P, Chen J, Chada KK, He C, Rosner MR: HMGA2/TET1/HOXA9 signaling pathway regulates breast cancer growth and metastasis. Proc Natl Acad Sci U S A 2013, 110:9920-9925.

70. Linderholm B, Lindh B, Tavelin B, Grankvist K, Henriksson R: p53 and vascular-endothelial-growth-factor (VEGF) expression predicts outcome in 833 patients with primary breast carcinoma. Int J Cancer 2000, 89:51-62.

71. Mohammed RA, Green A, El-Shikh S, Paish EC, Ellis IO, Martin SG: Prognostic significance of vascular endothelial cell growth factors $-A,-C$ and $-D$ in breast cancer and their relationship with angio- and lymphangiogenesis. Br J Cancer 2007, 96:1092-1100.

72. Cao YEG, Wang E, Pal K, Dutta SK, Bar-Sagi D, Mukhopadhyay D: VEGF exerts an angiogenesis-independent function in cancer cells to promote their malignant progression. Cancer Res 2012, 72:3912-3918. 
73. Petitjean A, Achatz MI, Borresen-Dale AL, Hainaut P, Olivier M:

TP53 mutations in human cancers: functional selection and impact on cancer prognosis and outcomes. Oncogene 2007, 26:2157-2165.

74. Langerød A, Zhao H, Borgan Ø, Nesland JM, Bukholm IR, Ikdahl T, Kåresen R, Børresen-Dale AL, Jeffrey SS: TP53 mutation status and gene expression profiles are powerful prognostic markers of breast cancer. Breast Cancer Res 2007, 9:R30.

doi:10.1186/1756-0500-7-871

Cite this article as: Maltseva et al: miRNome of inflammatory breast cancer. BMC Research Notes 2014 7:871.

\section{Submit your next manuscript to BioMed Central and take full advantage of:}

- Convenient online submission

- Thorough peer review

- No space constraints or color figure charges

- Immediate publication on acceptance

- Inclusion in PubMed, CAS, Scopus and Google Scholar

- Research which is freely available for redistribution 